\title{
Govier's "Invention" of the Theory of Argument
}

\section{RALPH H. JOHNSON}

Centre for Research in Reasoning, Argumentation and Rhetoric

University of Windsor

Windsor, Ontario

Canada N9B 3P4

johnsoa@uwindsor.ca

\begin{abstract}
In this paper, I propose that the inquiry known as a/the theory of argument is the "invention" of Trudy Govier, using that term in its rhetorical sense, viz., the process of choosing ideas appropriate to the subject. In her (1987) paper, "Is a Theory of Argument Possible?" Govier used the idea of theory of argument to focus her discussion on problems in argument analysis and evaluation that came to light in the 1970s and 1980s. The idea of a theory of argument was already there but Govier "discovered" it in the sense that she made its potential clear.
\end{abstract}

Résumé: Dans cet article, je propose que l'enquête connue sous le nom d'une/de la théorie de l'argument est «l'invention» de Trudy Govier. J'utilise ce terme dans son sens rhétorique, à savoir, le processus de choisir des idées appropriées à ce sujet. Dans son article publié en 1987, "Une théorie de l'argument est-elle possible?" Govier a utilisé l'idée de la théorie de l'argument pour concentrer sa discussion sur des problèmes reliés à l'analyse et l'évaluation d'arguments qui se sont révélés dans les années 1970 et 1980. L'idée d'une théorie de l'argument était déjà présent, mais Govier la «découvert» dans le sens qu'elle a rendu son potentiel clair.

Keywords: inferential adequacy, informal logic, logic, theory of analysis, theory of argument, theory of evaluation.

\section{Introduction}

In this paper, which is partly historical and partly conceptual and speculative, I propose that the inquiry known as a/the theory of ar- 
gument ${ }^{1}$ is the "invention" of Trudy Govier. I believe that after we see what she achieved in her paper "Is a Theory of Argument Possible?" (1987), we will be in position to appreciate its importance.

In that paper, Govier used the idea of theory of argument to focus on her discussion of a number of problems in argument analysis and evaluation that came to light in the 1970s and 1980s as a result of the emergence and development of Informal Logic. The idea of a theory of argument was there in the literature-as I will show-but Govier "discovered" it in the sense that she brought it to consciousness and made its importance evident.

In the next section, I provide the historical context for her discovery. In Section 3, I provide some background on the book in which the paper appeared: Problems in Argument Analysis Evaluation [PAEE]. In Section 4, I present Govier's idea of the theory of argument. In Section 5, I discuss the origins of the idea. Section 6 is my conclusion.

\section{The historical context}

Let me set the context. The (1987) paper that I focus on was, in an earlier version, delivered at the Second International Symposium on Informal Logic held in 1983. At that point in its history, Informal Logic was still a largely pedagogical initiative, slowly but surely moving in the direction of theoretical elaboration. At some intuitive level, it seems to me, Govier sensed that the discussion of the issues in argument analysis and evaluation required a different perspective - a more theoretical one-and that, I submit, is what stands behind her "invention" of the theory of argument.

\footnotetext{
${ }^{1}$ Here we encounter "a/the" ambiguity: $a$ theory of argument vs. the theory of argument. The way to disambiguate here is to follow the path taken in other areas: 'the theory of knowledge' refers to the general inquiry into the nature of knowledge; 'a theory of knowledge' refers to the attempt on the part of a particular theorist to put forth a satisfactory theory of knowledge. Within the theory of knowledge, there are causal theories, representative theories etc.; and within each of these types, one finds various individual attempts.
}

(C) Ralph H. Johnson. Informal Logic, Vol. 33, No. 2 (2013) pp. 98-115. 


\section{Background for Problems in Argument Analysis and Evalua- tion}

In 1987, Govier published Problems in Argument Analysis and Evaluation. Her book was significant because it was among the very first monographs to call attention to the work being done in the Informal Logic Movement. As we look at the contents of her volume, we see that the problems she has in mind were, most of them, problems that had arisen in the Informal Logic Movement.

What are the problems dealt with in this volume? The Table of Contents answers that question. Chapters 2 and 3 treat the idea of a theory of argument and examine a number of specific theories of argument. (I return to this matter shortly.) Chapter 4 examines two unreceived views of reasoning and argument: Wisdom's idea of case-by-case reasoning, and Wellman's notion of a conductive argument - a type of argument that had been overlooked and that Govier was calling to the attention of informal logicians. This is an issue for the typology of argument: in effect, Govier is arguing that the dichotomy (deductive or inductive) that underwrites so much theorizing is incomplete. Chapter 5 treats a problem that has received much attention in Informal Logic: the problem of how to supply missing premises. This problem is particularly vexing when one is treating arguments in their natural language setting (as contrasted with their presentation in logic textbooks) where there is often extraneous material that needs to be pared, as well as implicit material that needs to be put in play. Chapter 6 is a dialogue between Lysis and Charmides about some of the issues discussed thematically in other chapters, such as argument reconstruction and the principle of charity, and may be seen as mediating between Chapters 5 and 7 . Chapter 7 treats a crucial issue in the interpretation of argument: the principle of charity. When one is attempting to reconstruct an argument, what constraints are operative? Chapter 8 deals with the distinction commonly invoked when one is teaching students about argument, the distinction between an argument and explanation. Chapter 9 takes up the issue of fallacies, which are often invoked in the process of evaluating argument. One of the

(C) Ralph H. Johnson. Informal Logic, Vol. 33, No. 2 (2013) pp. 98-115. 
things that Informal Logic helped to do was too update the fallacy tradition by responding to Hamblin's famous castigation of it in Fallacies as "debased, worn out, and dogmatic" $(1970,12)$.

From this synopsis, it is evident that most of the problems dealt with in $P A A E$ are problems that emerged in the burgeoning Informal Logic Movement, which had begun in the late 70 s as a pedagogical initiative, born from the recognition that traditional logic did not do well by teaching students how to appraise the sorts of argument that they came across in their daily lives, in their personal lives and in their lives as citizens (Kahane 1971; Scriven 1976; Johnson and Blair 1977). As the movement developed, it became clear that these practical and pedagogical issues required theoretical attention and support. That gave rise to the 1978 Symposium, which was called to address just such issues. Govier was one of those who attended that Symposium. At the debriefing that took place at the end of the Symposium, it was recognized that there was a need for some form of communication: thus was born the Informal Logic Newsletter, edited by Johnson and Blair. ${ }^{2}$

Govier was one of the principal contributors to the Informal Logic Newsletter in those years and the list of articles below shows her focus on these issues:

Vol. 2, No. 2 (1979) Wellman`s Challenge and Response

Vol. 2, No. 3 (1979) More on Deductive and Inductive Arguments

Vol. 3, No. 1 (1980) Assessing Arguments: What Range of Standards?

Vol. 3, No. 3 (1980) Worries About Tu Quoque as a Fallacy

Vol. 4, No. 1 (1981) Uncharitable Thoughts About Charity

Vol. 4, No. 3 (1981) On Adler On Charity

Vol. 5, No. 1 (1983) Who Says There Are No Fallacies?

PAEE is important because there Govier attempted to meet the need for more theoretically oriented material. She was among the first to recognize the need to advance from the practical and peda-

\footnotetext{
${ }^{2}$ The Newsletter became the journal Informal Logic in 1984.

(C) Ralph H. Johnson. Informal Logic, Vol. 33, No. 2 (2013) pp. 98-115.
} 
gogical to the theoretical level and to respond to it. I believe that part of what led her to her focus on a theory of argument is that, at some intuitive level, Informal Logic needed theoretical ballast. In this vein, Govier writes:

My interest in the subjects covered in this book dates from 1978, when I came across several texts in applied, or informal logic, and was interested both by their practicality and by their recommendation for rethinking central philosophical traditions regarding logic and argument. I thought at that time that very fundamental issues were at stake but that the context of textbooks did not provide sufficient opportunities to explore them in depth. This book is an attempt to fill that gap. (ix)

The gap referred to here is that between practice and theory; PAEE is an attempt to bridge that gap by addressing many of these issues in the theory of argument.

\section{Govier on the idea of a theory of argument}

In her 1987 paper: "Is a Theory of Argument Possible?" (Chapter 4 of $P A E E$ ), Govier reviews and subjects to criticism several theories of argument: those that she attributes to McPeck, various versions of Deductivism, and what she calls spectral theories; and in the next paper, "The Great Divide," she critiques Positivism: the view that every argument is either deductive or inductive. But nowhere in these chapters does Govier offer a definition (explanation, elucidation) of exactly what she understands by a theory of argument.

However, she does two things that indicate she is relying on an intuitive sense of what a theory of argument is. First, she reviews and criticizes several theories of argument, as mentioned above. But none of the authors whose views she critiques have-to my knowledge — offered what they call a theory of argument; at least not in explicit terms; so Govier is engaged here in a kind of interpretation. She has some sense of what constitutes a theory of 
argument and she uses that to extract a theory of argument from texts that, while not claiming to contain a theory of argument, can, she believes, be seen as having one. Second, at two junctures in this paper (p. 13, and pp. 33-34), she offers a list of specifications that she clearly believes a theory of argument must satisfy. I believe we may take these as embodying or reflecting her intuitive notion of what a theory of argument is. I will take these passages up in detail shortly and attempt to extrapolate from them to her idea of a theory of argument.

We can begin the task of articulating her implicit notion of a theory of argument by taking her title seriously: Problems in Argument Analysis and Evaluation. It does not strike me as too much of a stretch to think that the basic components of a theory of argument would be a theory of argument analysis and a theory of evaluation. For the most part in her critique of the theories she considers, she focuses her critique on the theory of evaluation/appraisal to which that theory is committed. Govier admits she is largely focused on the question of whether the theory has a workable account of the inferential connection (or, inferential adequacy). Yet her specifications elsewhere of the items a theory of argument must address show that her own sense of what is required of a theory of argument is much richer.

Let me then turn to the passages in which Govier specifies tasks for a theory of argument.

\subsection{Govier on the components of a theory of argument}

Here is the text in which Govier presents this idea of the theory of argument:

Except in certain limited circles, there is no recognized subject called 'the theory of argument'. Yet there are clear a number of questions about arguing and argument not answered by formal logic and of considerable general interest. A theory of argument would discuss the nature and purpose of argument and specify and defend the standards for the appraisal of arguments. It would specify how many different

(C) Ralph H. Johnson. Informal Logic, Vol. 33, No. 2 (2013) pp. 98-115. 
types of argument there are and what standards are appropriate to assess each type. It would explain when and why it is reasonable to read into discourse statements which are not explicitly stated and whether and how the personalities and beliefs of the arguers and audiences logically affect the merit of argumentation. Ideally a theory of argument would apply to all natural arguments. But is there, or could there be, any such thing as theory of argument? (33)

From this passage, we may infer that, in Govier's view, a theory of argument would consist of at least the following components. Working with the division of labour proposed above - a theory of analysis and a theory of evaluation - the theory of analysis would contain the following components:

TA1: A discussion of the nature and purpose of argument.

TA2: A typology of arguments.

TA3: A method of argument reconstruction and furnishing.

The theory of evaluation would contain the following components:

TA4: Development of standards for the appraisal of argument.

TA5: A discussion of the role of arguer and audience belief in the merits of argumentation.

The focus of the theory of argument would be the domain of what she calls "natural arguments" (13). Another task for her theory of argument would be to offer an account of exactly what is meant by a "natural argument." This, we presume, would be a sub-item under TA1.

But there is more, for later she writes:

We are used to thinking of the study of argument as being primarily a matter of logic, and logic as being purely formal; hence the notion that we might need a nonformal theory of argument may seem novel or contrived. However, such questions as "how many different types of argument are 
there?" "When and why should we regard an argument as having missing premises?" and "Is the truth of the premises too strong a condition to demand for the soundness of arguments?" cannot be answered by formal techniques. (13)

The new item, "Is the truth of the premises too strong a condition to demand for the soundness of arguments?" would fall under T4, so we label it T4a. The other questions raised here have been covered in the previous description.

Here is the text where she acknowledges the task of inference assessment:

This account has emphasized a single problem throughout: inference assessment. Traditional logic virtually restricted itself to that dimension of argument appraisal, so that current theories tend also to emphasize. But this is not the only aspect of argument analysis which is open to theoretical scrutiny. (33)

I am going to assume that one other aspect she is thinking of is premise-adequacy. TA4 should, then, be subdivided as follows:

TA4i: Standards for evaluating inferential adequacy.

TA4ii: Standards for evaluating premise adequacy.

Govier adds these further comments about components of a theory of argument:

These issues arise from a preliminary examination of theories of argument primarily occupied with the traditional issue of inference appraisal. This is an indication of the fact that the topics in a full-fledged theory of argument will extend beyond the classification of arguments as to type and appraisal of the correctness of the inference they depend on, leading to broader issues of epistemology, pragmatics and dialectics. (34) (emphasis added) 
In other words, the assessment of arguments will require extralogical support: she mentions epistemology, pragmatics and dialectics.

These further topics fall broadly into two areas. One involves principles and policy having to do with the interpretation of discourse: The identification of arguments; the location of their premises and conclusions; the task of supplying unstated premises or conclusions; charity as a principle of interpretation; and the role of the arguer's intuitions and beliefs in proper interpretation. (34)

We may regard this as a further elaboration of the components of theory of analysis. This aspect of the theory of argument would develop principles for handling these tasks associated with argument analysis, largely to reconstruct the argument. Govier mentions:

- the identification of arguments

- the location of their premises and conclusions

- the task of supplying unstated premises

- charity as a principle of argument reconstruction

- the role of arguer intuition and beliefs in proper interpretation

The other additions have, Govier says, to do with the pragmatics and dialectics of argument. The question "whether premises in a good argument need to be true or only acceptable to an audience" lies at the core of the issue of premise-adequacy. She does not explain the connection between this issue and pragmatics, but it is easy enough to explain if we take 'pragmatics' here to be referring the role of the user of the expression. Next she mentions "whether the personal attributes of arguers having to do with their authority or credibility ever have legitimate bearing on their appraisal of the argument" (34). This seems to be a subitem under T5.

Finally she mentions: "...how rebuttals, pros and cons, and counterargument are to fit our structural models; and many related topics" (34). Govier seems to take these as issues about the structure, which would mean they would go under TA3. But her use of 
the term "dialectics" here is a bit of a puzzle, because it was not yet in widespread use in the vocabulary of those dealing with these issues. ${ }^{3}$ Here she seems to use the term to refer to the task of engaging with material like objections and counterarguments that come from a partner, respondent, or a member of the audience.

This completes my discussion of the specifications for a theory of argument as Govier elaborates them. Let me summarize the components of a theory of argument as Govier has set them forth.

In Govier's view as I have reconstructed it, a theory of argument has two parts: a theory of analysis and a theory of evaluation. For the theory of analysis, we have the following:

TA1: A discussion of the nature and purpose of argument.

TA2: A typology of arguments.

TA3: A method of argument reconstruction and furnishing missing premises.

The theory of evaluation would have the following:

TA4: Development of standards for the appraisal of argument.

TA4i: Standards for evaluating inferential adequacy.

TA4ii: Standard for evaluating premise adequacy.

TA5: A discussion of the role of arguer and audience belief in the merits.

The complete outline (with sub-items included) for a theory of argument then looks like this:

TA1: A discussion of the nature and purpose of argument.

TA2: A typology of arguments.

TA3: A method of argument reconstruction and furnishing missing premises.

TA3i: The identification of arguments.

\footnotetext{
${ }^{3}$ We know now that 1984 would mark the emergence of Pragma-dialectics, which brought about a much broader and deeper awareness of the dialectical dimension of argumentation. See van Eemeren and Grootendorst (1984).

(C) Ralph H. Johnson. Informal Logic, Vol. 33, No. 2 (2013) pp. 98-115.
} 
TA3ii: The location of their premises and conclusions.

TA3iii: The task of supplying unstated premises.

TA3iv: Charity as a principle.

TA3v: The role of arguer intuition and beliefs in proper interpretation.

TA3vi: The role of rebuttals, pros and cons, and counterarguments; how they fit structural models.

TA4: The development of standards for the appraisal of argument.

TA4i: Standards for evaluating inferential adequacy.

TA4ii: Standard for evaluating premise adequacy.

TA5: A discussion of the role of arguer and audience belief in the merits.

TA5i: The issue of whether the personal attributes of arguers having to do with their authority or credibility ever have legitimate bearing on their appraisal of the argument.

I take it that a fully developed theory of argument must not just treat these issues but must also present reasons that justify that treatment; that's what makes it a theory. Many textbooks contain approaches or ideas or policies on many of these matters, but these are typically not adequately grounded theoretically; ${ }^{4}$ they are simply laid down. That is why there was a need for theoretical development that Govier saw; it is the gap between theory and practice that the theory of argument is constructed to fill.

To summarise, I have been using her comments about a theory of argument to extract her intuitions about the content of a theory of argument. We have seen that it is quite robust and well developed.

Next, I want to ask: where did the idea of a theory of argument come from?

${ }^{4}$ Govier's own textbook; A Practical Study of Argument (1985), offers a fine illustration of how theoretical developments can be incorporated into texts.

(C) Ralph H. Johnson. Informal Logic, Vol. 33, No. 2 (2013) pp. 98-115. 


\section{Origins of the idea of a theory of argument}

\subsection{The recent history of the idea}

The notion of a theory of argument was used by Johnson and Blair in their First International Symposium (1980a) paper. In our discussion of "Principal Areas of Research" (7-8), we made mention of "(a) the theory of fallacy and (b) the theory of argument" (7). About the theory of argument we said this:

By "theory of argument" ... we mean the attempt to formulate a clear notion of the nature of argument which is not beholden to formal logical or proof-theoretic models, and to develop principles of criticism and reasoning which come close to shedding light on natural argumentation than do those of formal logic. (8)

In the Appendix, we set forth a list of "problems and issues in informal logic" (24-25). Item 2 reads as follows:

The theory of argument: What is the nature of argument? How is it related to reasoning? Is there a value to developing a typology of arguments? What are the standards that arguments ... should meet? (25)

In our gloss, we had the idea of a subdivision of the theory of argument into the theory of analysis and the theory of evaluation. Govier attended that conference and likely would have had access to the proceedings (Blair \& Johnson, 1980). So it is possible that this text was one of the sources that she drew on.

But then: how did that term come to the attention of Johnson and Blair? My conjecture is that both of us had been influenced by our reading of Hamblin's Fallacies. In Chapter 7, Hamblin observes that "the concept of argument is quite basic to logic but seldom examined" (p. 224). It seems clear from these comments that Hamblin sees the concept of argument as of vital importance to the study of fallacy and to Logic, and that he has undertaken to exam-

(C) Ralph H. Johnson. Informal Logic, Vol. 33, No. 2 (2013) pp. 98-115. 


\section{Ralph H. Johnson}

ine it here (though not in a systematic fashion). Later in the chapter Hamblin states: "All this sets the theory of arguments apart from Formal Logic and gives it an additional dimension" (p. 231). (The "this' refers to the claim that there are various criteria for the evaluation of argument.) Hamblin did spell out just what he understood by the term "the theory of arguments." (I assume that term is equivalent to what I have been calling "the theory of argument.") Nor am I aware of any source from which he might have borrowed it. It seems clear from the way his thoughts develop that this theory has something to do with the very concept of argument, and with how arguments are to be evaluated. Thus I take it that for Hamblin the theory of argument is an attempt to answer two fundamental questions: First, what is an argument? How is argument to be defined, conceptualized, differentiated from other $x$ 's to which it is analogous? Second, how is an argument to be evaluated? What are the appropriate standards by which it is judged? It seems likely that Hamblin's view influenced Johnson and Blair's discussion.

\subsection{The theory of argument: A sketch of some historical anteced- ents}

If one now asks about the historical antecedents of the theory of argument, one must distinguish between the idea of a theory of argument, and the occurrence of the term itself as designating a specific inquiry. None of the authors I treat below uses the term "theory of argument."

When it comes to logic and the study of argument, all roads lead back to Aristotle. One can certainly view the Prior Analytics and Posterior Analytics as containing a theory of argument. There Aristotle has a definition of argument (syllogism); he provides a comprehensive treatment of argument structure and a theory of evaluation. Subsequent historical developments are too complex to undertake here, so I will flash forward to the $20^{\text {th }}$ Century.

The first entry would be Toulmin's The Uses of Argument (1958) where Toulmin put forth his theory of argument. That theory takes a radical approach to the way in which we view the struc-

(c) Ralph H. Johnson. Informal Logic, Vol. 33, No. 2 (2013) pp. 98-115. 
ture of arguments, revolving around the notion of a warrant-a term that has proven to be hugely important in the subsequent history: Freeman (2005) Hitchcock (2003) and Pinto (2001). ${ }^{5}$ When it comes to evaluation, Toulmin invokes a field theory that locates the talk of argument evaluation in the field to which the argument's warrant belongs.

As has already been mentioned, Hamblin published Fallacies in 1970, which contains an explicit mention of the theory of arguments. ${ }^{6}$ Finocchiaro (1980) refers to Hamblin's theory of argument:

A second overwhelming fact about our data is that arguments are normally complex. ... So one may expect great differences between an approach that takes complex arguments as fundamental, and one that takes simple ones as fundamental. The usual accounts follow the latter, and hence they are probably not merely a simplification but an oversimplification. These considerations accord very well with Hamblin's theory of argument. (418)

I have here dealt only with a few instances of theories of argument from the tradition of logic. There are other traditions, notably rhetoric and dialectics, in which argumentation has been studied and which certainly may be construed as involved in the development of a theory of argument. But I cannot undertake here the task of discussing what occurred in these traditions.

I turn now to my final topic: the importance of Govier's invention.

\footnotetext{
${ }^{5}$ For a less enthusiastic review of Toulmin's approach, see my (1981).

6 I believe that in Chapter 7 of Fallacies, Hamblin developed what I call a "latent" theory of argument, the details of which I will be discussing in a forthcoming paper.
}

(C) Ralph H. Johnson. Informal Logic, Vol. 33, No. 2 (2013) pp. 98-115. 


\section{Ralph H. Johnson}

\section{The importance of Govier's invention}

What are the achievements of this paper? First, Govier succeeded in calling attention to the theory of argument, an inquiry that had not hitherto received much attention. Second, she developed the idea further by specifying some of the tasks that such a theory must undertake; these were discussed above. Third, she reviewed several theories of argument and argued that they were not adequate, largely on the ground that their accounts of inferential connection were deficient - thereby flagging that as an issue for future theorists. Fourth, she called for better theories of argument and if we read between the lines we can see that she also gave us some thoughts about what would be required for such a theory:

- A better theory of argument would have a coherent account of the inferential connection.

- A better theory of argument would add a coherent account of premise adequacy.

- A better theory of argument would require support from other disciplines; she mentioned pragmatics, epistemology and dialectics. (Assumed, I believe, is that such a theory would also have input from logics: especially informal logic.)

Naturally, as the theory of argument develops, there will be questions about the relation of the theory of argument to other inquiries such as informal logic and Argumentation Theory, but those are not matters I can deal with here. My purpose here was to call attention to the groundbreaking work done by Govier in her $(1983 / 1987)^{7}$, “Is a theory of argument possible?" That paper brought the idea of a theory of argument to the next stage of development.

Did Govier invent the Theory of Argument? It depends on what you take 'invent' to mean and what you take "the theory of

\footnotetext{
${ }^{7}$ The first of two dates refers to the year of presentation; the second, to the year of publication.

(C) Ralph H. Johnson. Informal Logic, Vol. 33, No. 2 (2013) pp. 98-115.
} 
argument" to comprise? If your paradigm is Edison's invention of the light bulb, then no, she did not invent the theory of argument. The term was already there, in the literature, prior to her (1983/1987) but it was just barely there. It first appeared in Hamblin in 1970, but he did nothing with it. Then it appears in Johnson and Blair (1978/1980a), where it was given a bit more flesh on its bones. But the full fleshing out did not occur until Govier 1983/1987. She constituted it as a theory by positioning it in the way I have discussed. In that sense the theory of argument is her invention and an important contribution to the study of argument.

Acknowledgements: Thanks to Tony Blair for his most helpful comments on previous versions of this paper. Thanks also to Maurice Finocchiaro, Frans van Eemeren and David Zarefsky for their assistance. Thanks to Michael Baumtrog for his assistance formatting and for helpful comments on the paper.

\section{References}

Blair, J.A. (2012). Groundwork in the Theory of Argumentation. Dordrecht: Springer.

Blair J.A. \& R.H. Johnson (Eds.). (1980). Informal Logic: The First International Symposium. Point Reyes, CA: Edgepress.

Eemeren, F.H. van \& R. Grootendorst. (1984). Speech Acts in Argumentative Discussions. Dordrecht: Foris.

Finocchiaro, M.A. (1980). Galileo and the Art of Reasoning. Boston Studies in the Philosophy of Science, No. 61. Dordrecht: Reidel [now Springer].

Freeman, J.B. (2005). Acceptable Premises: An Epistemic Approach to an Informal Logic Problem. New York: Cambridge University Press.

Govier, T. (1979). "Wellman`s Challenge and Response." Informal Logic Newsletter 2(2): 10-15. 
Govier, T. (1979). "More on Deductive and Inductive Arguments." Informal Logic Newsletter 2(3): 7-8.

Govier, T. (1980). "Assessing Arguments: What Range of Standards?" Informal Logic Newsletter 3(1): 2-4.

Govier, T. (1980). "Worries About Tu Quoque as a Fallacy." Informal Logic Newsletter 3(3): 2-4.

Govier, T. (1981). "Uncharitable Thoughts About Charity." Informal Logic Newsletter 4(1): 5-6.

Govier, T. (1981). "On Adler On Charity." Informal Logic Newsletter 4(3): 10-11.

Govier, T. (1983). "Who Says There Are No Fallacies?" Informal Logic 5(1): 2-10.

Govier, T. (1985). "Logical Analogies." Informal Logic 7(1): 2733.

Govier, T. (1985). A Practical Study of Argument. Belmont, CA: Wadsworth.

Govier, T. (1987). Problems in Argument Analysis and Evaluation. Dordrecht: Foris.

Hamblin, C.L. (1970). Fallacies. London: Methuen.

Hitchcock, D. (2003). “Toulmin's Warrants.” In F.H. van Eemeren, J.A. Blair, C.A. Willard \& A.F. Snoeck Henkemans (Eds). Anyone who has a View: Theoretical Contributions to the Study of Argumentation, pp. 69-82. Dordrecht: Kluwer Academic Publishers.

Johnson, R.H. (1981). “Toulmin's Bold Experiment: An Appreciation and Critique of Toulmin's An Introduction to Reasoning." Informal Logic Newsletter 3(2): 16-27, and 3(3): 13-20.

Johnson, R.H. \& J.A. Blair. (1977). Logical Self-Defense. (3rd edition, 1993). Toronto: McGraw-Hill Ryerson. First United States edition: 1994. New York: McGraw-Hill. New United States edition: 2006: New York: IDEA Press.

Johnson, R.H. \& J.A. Blair (1980a). "The Recent Development of Informal Logic." In J.A. Blair and R.H. Johnson (Eds.), Informal Logic: The First International Symposium, pp. 3-28. Inverness, CA: Edgepress.

(C) Ralph H. Johnson. Informal Logic, Vol. 33, No. 2 (2013) pp. 98-115. 
Johnson, R.H. \& J.A. Blair (1980b). “A Bibliography of Recent Work in Informal Logic.” In J.A. Blair and R.H. Johnson (Eds.), Informal Logic: The First International Symposium, pp. 163-72. Inverness, CA: Edgepress.

Kahane, H. (1971). Logic and Contemporary Rhetoric. (8th edition, 1997), with N. Cavender. Belmont, CA: Wadsworth

Pinto, R.C. (2001). Argument, Inference and Dialectic. Dordrecht: Kluwer.

Scriven, M. (1976). Reasoning. New York: McGraw-Hill.

Toulmin, S.E. (1958). The Uses of Argument. Cambridge: Cambridge University Press.

(C) Ralph H. Johnson. Informal Logic, Vol. 33, No. 2 (2013) pp. 98-115. 